Int. J. Electrochem. Sci., 14 (2019) 3315 - 3325

International Journal of

ELECTROCHEMICAL

SCIENCE

WWW.electrochemsci.org

\title{
Electrochemical and Catalytic Studies of Cysteine Oxidation Induced by an Organic p-n bilayer both under Illumination and in the Dark
}

\author{
Ryuhei Watanabe and Toshiyuki Abe* \\ Department of Frontier Materials Chemistry, Graduate School of Science and Technology, Hirosaki \\ University, 3 Bunkyo-cho, Hirosaki 036-8561, Japan \\ *E-mail: tabe@hirosaki-u.ac.jp
}

doi: $10.20964 / 2019.04 .17$

Received: 13 December 2018 / Accepted: 22 January 2019 / Published: 10 March 2019

As found recently by our group, dual-functional catalysis represents a specific chemical process that can induce a redox reaction not only under illumination but also in the dark. In a previous study, an organic p-n bilayer, comprising 3,4,9,10-perylenetetracarboxylic-bis-benzimidazole (PTCBI) and cobalt(II) phthalocyanine ( $\mathrm{CoPc})$, was utilized as a catalyst in the presence of 2-mercaptoethanol. Amino acids are attractive targets for studying dual catalysis because they bear various electrondonating groups such as $-\mathrm{COOH},-\mathrm{NH}_{2},-\mathrm{OH}$, and $-\mathrm{SH}$. In this work, cysteine (Cys) was subjected to dual catalysis reaction assisted by the PTCBI/CoPc bilayer. Similar to the aforementioned study, the organo-bilayer showed dual-catalytic activity for the oxidation of Cys along with the reduction of $\mathrm{H}^{+}$ to $\mathrm{H}_{2}$, where the Cys oxidation can be considered to occur at the top end of the valance band $\left(\mathrm{Co}^{\mathrm{III}} \mathrm{Pc}\right)$ and at the bottom end of the conduction band $\left(\mathrm{Co}^{\mathrm{II}} \mathrm{Pc}\right)$ with and without irradiation, respectively. Based on the results obtained by employing serine (Ser) as a reference compound, it appeared that the dissociated thiol group of Cys is responsible for the dual catalysis by the organo-bilayer.

Keywords: organic semiconductors; p-n bilayer; photocatalysis; catalysis; cysteine

\section{$\underline{\text { FULL TEXT }}$}

(C) 2019 The Authors. Published by ESG (www.electrochemsci.org). This article is an open access article distributed under the terms and conditions of the Creative Commons Attribution license (http://creativecommons.org/licenses/by/4.0/). 